\title{
Strasbourg Welcomes 1989 E-MRS Meeting Participants
}

The Council of Europe and European Parliament, Strasbourg, France, once again welcomes participants to the 1989 Meeting of the European Materials Research Society, May 30 - June 2, 1989. A full complement of meeting activities is planned for this popular venue, including plenary speakers, four technical symposia, an intensive course on high-tech biomaterials, and a special seminar to facilitate business opportunities between European and American companies dealing in biomaterials and medical devices.

\section{E-MRS Meeting Registration}

Registration can be made in advance or at the E-MRS Meeting. Fees:

Before May 15, $1989 \quad 1,700 \mathrm{FF}$

After May 15, $1989 \quad 2,000$ FF

At-meeting registration is scheduled for May 29, 1989, 2:30 to 6:00 p.m. at the Council of Europe.

Reduced fees are available for students and require proof of university registration:

Before May 15, $1989 \quad 700 \mathrm{FF}$

After May 15, $1989 \quad 900 \mathrm{FF}$

For registration forms and information about the E-MRS Meeting, contact:

C.R.N.

Attention P. Siffert

B.P. 20

F-67037 Strasbourg Cedex, France

Telephone: 88286543

Telex: CNRS CRO $890032 \mathrm{~F}$

Fax: 88280990

\section{Plenary Session}

Four invited lectures will be presented during the plenary session the morning of May 30. The speakers and their topics are:

- Prof. J. Friedel (Laboratoire de Physique des Solides, Orsay, France) "Bonding in Clusters and Condensed Matter: The Role of Electron Correlations."

- Prof. K. Von Klitzing (Max Planck Institut fïr Festkörperforschung, Stuttgart, West Germany) "Quantum Phenomena in Semiconductors."

- Prof. L. Belmain (Director, SCIENCE Program, Commission of the European Communities-DG XII, Brussels, Belgium) "The SCIENCE Program."

- Prof. G. Metakides (Director, ESPRIT RESEARCH Program, Commission of the European Communities-DG XIII, Brussels, Belgium) "The ESPRIT Program."

Symposium A-Third International Symposium on Silicon Molecular Beam Epitaxy

Chairs: E. Kasper, AEG Research Center,
West Germany; E.H.C. Parker, University of Warwick, United Kingdom.

This will be the third international symposium dealing with single-crystal growth, by $\mathrm{MBE}$, of materials compatible with silicon, their physical characterization, and device application. Discussions will cover: homoepitaxy-preparation, characterization, alternative growth methods; dopingco-vaporation, implantation, solid-phase $\mathrm{MBE}$; heteroepitaxy-nucleation (including III/V on Si), mismatch accommodation, germanium silicon, silicides, insulators; quantum wells and superlattices-theory, properties, ultrathin periods; deviceswork to date and prospects for exploiting MBE capabilities; and apparatus-scaling towards production, in situ monitoring, advances.

Invited speakers include: G. Abstreiter, B. Bosch, T.P. Pearsall, P. Grunthaner, R. Hull, S. Iyer, H. v. Känel, E. Lightowlers, J.F. Luy, I.E. Sundgren, T. Tatsumi, A. Zunger.

\section{Symposium B-Science and Technology of Defects in Silicon}

Chairs: C.A.J. Ammerlaan, Natuurkundig Laboratorium, University of Amsterdam, the Netherlands; A. Chantre, Centre National d'Etudes des Télécommunications, France; P. Wagner, Heliotronic $\mathrm{GmbH}$, West Germany.

This symposium will highlight recent developments in the materials science of silicon. Topics will range from the fundamental characterization of the physical properties to the assessment of materials for device applications. Sessions are scheduled on crystal growth (bulk, epitaxial, SOI), process-induced defects (dry etching, heat-treatment, lithography, ion implantation), gettering, topography (imaging, mapping), hydrogen passivation, impurities (fast diffusing metals, light and exotic impurities), complexes and interactions between impurities (impurity pairs, thermal donors), and mechanical properties.

Invited speakers include: $W$. Bergholz, K. Graff, T. Gregorkiewicz, L.L. Jastrzebski, K. Maex, G. Oehrlein, J.A. Pals, F. Ponce, J.L. Regolini, K. Sumino, W. Zulehner.

\section{Symposium C-Acoustic, Thermal Wave and Optical Characterization of Materials}

Chairs: G.M. Crean, National Microelectronics Research Center, Ireland; M. Locatelli, Institut de Recherche Fondamentale Centre d'Etudes Nucléaires de Grenoble,
France; J. McGilp, Trinity College, Ireland.

This symposium will feature novel nondestructive techniques for characterizing materials, processes and devices. It is intended to bring together both theoreticians and experimentalists working on the acoustic, thermal wave and optical response of materials. Emphasis will be on probe-specimen interactions, in situ diagnosis, instrumentation developments and trends. Topics include:

- Acoustic microscopy of materials, surface acoustic wave characterization techniques, surface acoustic wave propagation theory, acoustic techniques for on-line nondestructive evaluation.

- Photo-thermal wave analysis, photoacoustic microscopy, thermal wave propagation and scattering.

- Optical microscopy, IR and Raman spectroscopy, fluorescence, spectroscopic ellipsometry, optical second harmonic generation, optical reflectivity and differential reflectance, theory of optical response.

Invited speakers include: B.A. Auld, D. Fournier, R. Del Sole, R.P. Huebener, C.K. Jen, J.A. Woollam, A. Alippi, H. Vetters.

\section{Symposium D-Beam Processing and Laser Chemistry}

Chairs: I.W. Boyd, University College London, United Kingdom; E. Rimini, University of Catania, Italy.

This symposium will deal with both practical and theoretical aspects of energy beam processing of bulk maierials, thin films, and surfaces. A large degree of focus will be given to the use of ion, electron and photon beams, and to laser-assisted process chemistry. Thin film and surface and interface reactions as well as bulk phase transformations will be emphasized, in addition to practical technological details and the criteria for present and future applications.

Sample topics include: effect of energy beams on surface and interface reactions; bulk and surface transformations induced by energy beams; studies of kinetics and thermodynamics of the stimulated reaction process; deposition, growth and patterning of thin films; and applications technology of energy beams including in situ processing and device manufacturing.

Invited speakers include: G. Auvert, T.S. Baller, N. Hecking, J.E. Epler, A. Golanski, E.E. Marinero, S.M. Metev, W.I. Milne, F. Priolo, W.C. Sinke, M. Stuke, J.I.D. Wilson, Y. Yamada. 


\section{Symposium E-Biomaterials}

Chairs: D. Muster, L.E.E.D. Biomatériaux, France; G. Hastings, Biomedical Engineering Unit Medical Institute, Hartshill, United Kingdom.

This symposium aims to bring together biomedical practitioners, scientists and manufacturers, jurists, and economists for exchanging ideas and expertise on the real trends in European basic and applied research on biomaterials, in hard tissue repair and reconstruction, as well as their consequences for both the industry and the society.

The 1989 theme, "Interfaces in Biomaterials Sciences," will cover physical, chemical and biological interfaces together with the interfaces between legal, socioeconomical, and biomedical sciences. Four sessions are planned: Surface Characterization and Treatment; Interactions and Their Control (tissue and material responses); Clinical Aspects (orthopaedics, dental and maxillo-facial surgery); and Socio-economical and Legal Aspects (biomaterials industry in Europe, marketing approach, standardization, liability problems).

Invited speakers include: $M$. Davies, $P$. Christel, H. Oonishi, S. Perren, K. Mattox.

\section{European Intensive Course on High-Tech Biomaterials in Hard Tissue Repair or Replacement}

Coordinator: D. Muster, L.E.E.D. Biomatériaux, France.

This course will run during the E-MRS meeting, May 30-June 2. It requires separate registration (available from $\mathrm{P}$. Siffert at the E-MRS Meeting address) but provides an opportunity to attend the E-MRS Symposium on Biomaterials. The course is intended for all those with a common interest in health care and materials: scientists, practitioners, manufacturers, designers, managers, economists, insurance representatives, members of international organizations, and postgraduate students. Through multidisciplinary interactions and a scholarly atmosphere, the course aims to provide a creative environment for transferring technology from the applied research laboratory to industry.

A roster of leading specialists worldwide will present detailed lectures (postgraduatel third cycle level) on the following topics and more: current use of high-technology materials for biomedical application; development of new materials for reconstructing tissues and organs; HTBM faced with the human body (biostability or biodegradability, biocompatibility, biofunctionability); evaluation of HTBM and liability litigation; HTBM and (long) life quality; industrial problems; HTBM in biomedical business;
HTBM and battlefield surgery; HTBM and drug delivery systems; surgical techniques adapted to high-tech biomaterials, etc.

\section{Biomedical Materials and Medical}

\section{Devices Seminar}

At a one-day seminar, June 3, just after the E-MRS Meeting in Strasbourg, biomaterials and medical device representatives from Europe and the United States can meet to consider mutually beneficial business opportunities. Participants will learn about the legal, technical, and marketing aspects of the global medical market. The seminar is being organized by Webster University and Milex Consultants, Geneva.

Roundtable discussions will focus on: research trends and product developments; perspectives in the ECC, EFTA, and the
USA; technology transfer and corporate partnering; product liability and regulatory considerations; and future markets in the United States, Western Europe, and Eastern Europe.

Speakers include: K. Mattox, K.M. \& Associates, St. Paul, Minnesota, USA; D. Muster, vice president, Biomaterials Group, Council of Europe, Strasbourg; J.M. Price, partner, Feagre \& Benson, Minneapolis, Denver, London; and P. Kukorelly, Milex Consultants, Geneva.

For information contact: Webster University, 15, rte de Collex, CH-1293 Bellevue/ GE, telephone (41) 227424 52; or Milex Consultants, Postfach $5236, \mathrm{CH}-6330 \mathrm{Ch}$ a $\mathrm{m}$, telephone (41) 424141 96, fax (41) 4241 6065 .

\title{
PROMPT SHIPMENT of MRS BOOKS to EUROPE, the MIDDLE EAST, and AFRICA by CLARKE ASSOCIATES-EUROPE LIMITED
}

\author{
Clarke Associates-Europe Limited now offers MRS book buyers in 30 \\ European countries, 12 Middle East territories, and all of Africa:
}

$\checkmark$ The ease of making payment in any major currency

$\checkmark$ No prepayment or proforma requirement

$\checkmark$ Faster shipment of MRS Symposium Proceedings, Conference Proceedings, and Extended Abstracts from UK stocks

$\checkmark$ MRS members can buy at MRS member rates (plus a small handling charge)

European countries include: Austria, Belgium, Bulgaria, Cyprus, Czechoslovakia, Denmark, Finland, France, Germany (Federal and Democratic Republics), Greece, Hungary, Iceland, Ireland, Israel, Italy, Luxembourg, Malta, Netherlands, Norway, Poland, Portugal, Romania, Spain, Sweden, Switzerland, Turkey, United Kingdom, USSR, Yugoslavia.

Middle East territories include: Bahrein, Egypt, Iran, Iraq, Jordan, Kuwait, Lebanon, Libya, Saudi Arabia, Syria, United Arab Emirates, Yemen.

Africa includes the entire continent.

\section{NEW ADDRESS}

Clarke Associates-Europe Limited

13a Small Street, Bristol BS1 1DE, United Kingdom

Telephone: 0272268864

Fax: 0272226437 